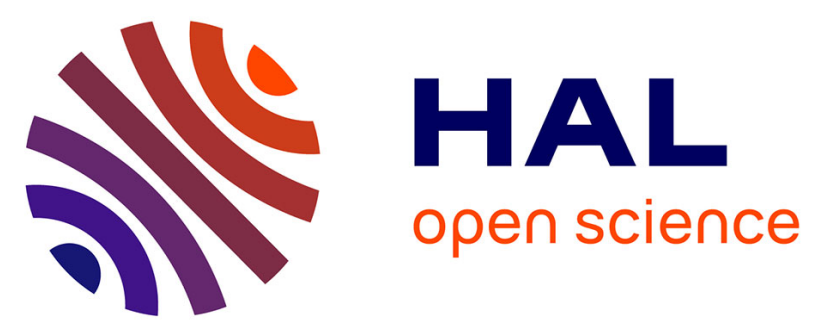

\title{
Radiation belt electron precipitation due to geomagnetic storms: Significance to middle atmosphere ozone chemistry
}

Craig J. Rodger, Mark A. Clilverd, Annika Seppälä, Neil R. Thomson, Rory J. Gamble, Michel Parrot, Jean-andré Sauvaud, Thomas Ulich

\section{To cite this version:}

Craig J. Rodger, Mark A. Clilverd, Annika Seppälä, Neil R. Thomson, Rory J. Gamble, et al.. Radiation belt electron precipitation due to geomagnetic storms: Significance to middle atmosphere ozone chemistry. Journal of Geophysical Research Space Physics, 2010, 115, A11320 (12 p.). 10.1029/2010JA015599 . insu-01254033

\section{HAL Id: insu-01254033 \\ https://hal-insu.archives-ouvertes.fr/insu-01254033}

Submitted on 11 Jan 2016

HAL is a multi-disciplinary open access archive for the deposit and dissemination of scientific research documents, whether they are published or not. The documents may come from teaching and research institutions in France or abroad, or from public or private research centers.
L'archive ouverte pluridisciplinaire HAL, est destinée au dépôt et à la diffusion de documents scientifiques de niveau recherche, publiés ou non, émanant des établissements d'enseignement et de recherche français ou étrangers, des laboratoires publics ou privés. 


\title{
Radiation belt electron precipitation due to geomagnetic storms: Significance to middle atmosphere ozone chemistry
}

\author{
Craig J. Rodger, ${ }^{1}$ Mark A. Clilverd, ${ }^{2}$ Annika Seppälä, ${ }^{2,3}$ Neil R. Thomson, ${ }^{1}$ \\ Rory J. Gamble, ${ }^{1}$ Michel Parrot, ${ }^{4}$ Jean-André Sauvaud, ${ }^{5}$ and Thomas Ulich $^{6}$ \\ Received 25 April 2010; revised 4 August 2010; accepted 11 August 2010; published 20 November 2010.
}

[1] Geomagnetic storms triggered by coronal mass ejections and high-speed solar wind streams can lead to enhanced losses of energetic electrons from the radiation belts into the atmosphere, both during the storm itself and also through the poststorm relaxation of enhanced radiation belt fluxes. In this study we have analyzed the impact of electron precipitation on atmospheric chemistry (30-90 km altitudes) as a result of a single geomagnetic storm. The study conditions were chosen such that there was no influence of solar proton precipitation, and thus we were able to determine the storm-induced outer radiation belt electron precipitation fluxes. We use ground-based subionospheric radio wave observations to infer the electron precipitation fluxes at $L=3.2$ during a geomagnetic disturbance which occurred in September 2005. Through application of the Sodankylä Ion and Neutral Chemistry model, we examine the significance of this particular period of electron precipitation to neutral atmospheric chemistry. Building on an earlier study, we refine the quantification of the electron precipitation flux into the atmosphere by using a time-varying energy spectrum determined from the DEMETER satellite. We show that the large increases in odd nitrogen $\left(\mathrm{NO}_{x}\right)$ and odd hydrogen $\left(\mathrm{HO}_{x}\right)$ caused by the electron precipitation do not lead to significant in situ ozone depletion in September in the Northern Hemisphere. However, had the same precipitation been deposited into the polar winter atmosphere, it would have led to $>20 \%$ in situ decreases in $\mathrm{O}_{3}$ at $65-80 \mathrm{~km}$ altitudes through catalytic $\mathrm{HO}_{x}$ cycles, with possible additional stratospheric $\mathrm{O}_{3}$ depletion from descending $\mathrm{NO}_{x}$ beyond the model simulation period.

Citation: Rodger, C. J., M. A. Clilverd, A. Seppälä, N. R. Thomson, R. J. Gamble, M. Parrot, J.-A. Sauvaud, and T. Ulich (2010), Radiation belt electron precipitation due to geomagnetic storms: Significance to middle atmosphere ozone chemistry,

J. Geophys. Res., 115, A11320, doi:10.1029/2010JA015599.

\section{Introduction}

[2] Relatively small changes in the outflow of particles from the Sun can trigger geomagnetic storms [Sharma et al., 2004], which produce large changes in radiation belt populations. Typically, the relativistic electron population "drops out" during the main phase of a storm. However, within $\sim 1$ day the population "recovers" to a level that may or may not be greater than the prestorm level, but can be several orders of magnitude larger. Essentially all geomagnetic storms substantially alter the electron radiation belt populations [Reeves et al., 2003]. Geomagnetic storms triggered by both

\footnotetext{
${ }^{1}$ Department of Physics, University of Otago, Dunedin, New Zealand.

${ }^{2}$ British Antarctic Survey, Cambridge, United Kingdom.

${ }^{3}$ Also at Earth Observation, Finnish Meteorological Institute, Helsinki, Finland.

${ }^{4}$ Laboratoire de l'Environnement et de l'Espace, Orleans, France.

${ }^{5}$ Centre d'Etude Spatiale des Rayonnements, Toulouse, France.

${ }^{6}$ Sodankylä Geophysical Observatory, University of Oulu, Sodankylä, Finland.

Copyright 2010 by the American Geophysical Union. 0148-0227/10/2010JA015599
}

coronal mass ejections and high-speed solar wind streams lead to enhanced losses from the radiation belts into the atmosphere [e.g., Clilverd et al., 2007a; Rodger et al., 2010], not only during the storm itself but also through the poststorm relaxation of enhanced radiation belt fluxes [e.g., Rodger et al., 2007].

[3] The precipitation of highly energized electrons couples Earth's radiation belts to the middle and upper atmosphere (30-90 km altitudes). Energetic electron precipitation results in the enhancement of odd nitrogen $\left(\mathrm{NO}_{x}\right)$ and odd hydrogen $\left(\mathrm{HO}_{x}\right)$, which play a key role in the ozone balance of the middle atmosphere because they destroy odd oxygen $\left(\mathrm{O}_{x}=\right.$ $\mathrm{O}+\mathrm{O}_{3}$ ) at different altitudes through catalytic reactions [Lary, 1997; Grenfell et al., 2006]. Observations of significant $\mathrm{NO}_{x}$ increases have been reported directly associated with energetic electron precipitation [Clilverd et al., 2009a], leading to subsequent ozone losses [e.g., Seppälä et al., 2007]. The Clilverd et al. [2009a] study appears to be the first observational evidence of in situ $\mathrm{NO}_{x}$ production into the lower mesosphere, but alternative explanations may exist. For example, $\mathrm{NO}_{2}$ nighttime measurements at similar latitudes from the Envisat/MIPAS instrument show a similar, but possibly 
smaller, increase occurring at a similar time, which however correspond to a decrease of $\mathrm{CH}_{4}$ [López-Puertas et al., 2006]. This could therefore be interpreted as the signature of strong descent in the polar vortex, rather than in situ production. However, this explanation does not rule out in situ $\mathrm{NO}_{x}$ production consistent with the experimental observations of strong relativistic electron precipitation and the measurements of associated increased ionization density in the lower ionosphere, as reported initially by Clilverd et al. [2007c], and analyzed in detail by Clilverd et al. [2009a]. Turunen et al. [2009] produced a recent overview of the impact of different energies of precipitating particles on $\mathrm{NO}_{x}$ generation in the middle and upper atmosphere. When particle precipitation occurs in the polar regions during the winter darkness, the long-lived $\mathrm{NO}_{x}$ produced is confined by the polar vortex, and descends downward within it to stratospheric altitudes throughout the winter [e.g., Callis et al., 1996; Funke et al., 2005; López-Puertas et al., 2006; Seppälä et al., 2007], producing significant indirect impacts on stratospheric ozone [Randall et al., 2005].

[4] Ozone affects the radiative balance, temperature, and dynamics of the atmosphere owing to its capability of absorbing solar UV radiation efficiently [Brasseur and Solomon, 2005], and thus may couple to climate forcing [Haigh et al., 2005]. Model results showed that ozone reductions in the stratosphere lead to changes in temperature and could possibly effect atmospheric circulation through variations in the zonal winds (QBO, Quasi Biennial Oscillation) [Elias and Zossi de Artigas, 2003; Langematz et al., 2005]. Rozanov et al. [2005] imposed a $\mathrm{NO}_{x}$ source calculated from 1987 NOAA TIROS spacecraft energetic electron precipitation (EEP) measurements to represent this linkage into their chemistry-climate model, and found large $( \pm 2 \mathrm{~K})$ variations in polar surface air temperatures. They concluded that the magnitude of the atmospheric response to EEP events could potentially exceed the affects from solar UV fluxes. Very recently, the pattern and magnitude of the polar surface air temperature variability predicted by Rozanov et al. [2005] has been observed in European Centre for Medium-Range Weather Forecast ERA-40 reanalysis data, with the surface air temperature variability associated with geomagnetic disturbances being roughly twice that associated with solar cycle UV variability [Seppälä et al., 2009].

[5] Few ground based data sets have the combination of long time series and near-global spatial coverage to describe the variation in precipitation into the atmosphere. The AARDDVARK array of subionospheric radio receivers [Clilverd et al., 2009b], and the GLORIA riometer array [Alfonsi et al., 2008] are examples of relevant, but currently limited, ground-based instruments. There are also few spacecraft measurements available that measure precipitating electron fluxes and energy spectra in the bounce loss cone for the energy range $>20 \mathrm{keV}$, and which have flown for sufficiently long time periods. Some satellite measurements of electron precipitation properties have been available for more than a solar cycle (e.g., SAMPEX, POES). However, each satellite instrument has some limitations in either spatial resolution, or energy resolution, or suffers from low-energy proton contamination (see Rodger et al. [2010] for a discussion of some of these issues), or has an inability to adequately resolve the $\mathrm{drift} /$ bounce loss cone. These issues result in uncertainties as to the actual loss rates of electrons into the atmosphere when measured from satellites.

[6] Ground-based measurements of the lower ionosphere can help contextualize satellite measurements of electron precipitation, and in some cases will provide more reliable continuous observations of the energy flux into the middle atmosphere. For electrons $>100 \mathrm{keV}$, the bulk of the precipitated energy is deposited into the middle and upper atmospheric levels $(\sim 30-90 \mathrm{~km})$, and hence causes the lower ionospheric boundary (the $D$ region), to shift downward. One of the few experimental techniques which can probe these altitudes uses VLF electromagnetic radiation, trapped between the lower ionosphere and Earth [Barr et al., 2000]. The nature of the received radio waves is largely determined by propagation between these boundaries [e.g., Cummer, 2000]. Significant variations in the received amplitude and/or phase of fixed frequency VLF transmissions arise from changes in the lower ionosphere, for example, the additional ionization produced by energetic particle precipitation. VLF radio wave propagation has been shown to be sensitive to relativistic electron precipitation events during geomagnetic disturbances [Thorne and Larsen, 1976; Clilverd et al., 2006b]. The effect on the signals can be either an increase or decrease in signal amplitude, depending on the modal mixture of each signal observed. Further discussion of the use of subionospheric VLF propagation as a remote sensing probe can be found in recent review articles [e.g., Barr et al., 2000; Rodger, 2003]. Observations of subionospheric VLF transmissions permit observers to study energetic particle precipitation from locations remote from the actual precipitation region, and recent studies have demonstrated how precipitation flux measurements can be extracted from observed subionospheric VLF changes [Rodger et al., 2007, 2008; Clilverd et al., 2008].

[7] In this study we improve our earlier analysis of the subionospheric VLF to better quantify the time-varying precipitation flux of electrons into the atmosphere, by modeling the effect of the satellite-measured changing electron energy spectra. These precipitation fluxes are then input to into the Sodankylä Ion and Neutral Chemistry (SIC) model. The SIC model outputs are used to (1) confirm the simple ionospheric modeling and hence confirm the precipitation fluxes, and (2) determine the significance of the neutral atmosphere chemical changes driven by this precipitation. We particularly focus on ozone losses, as changes in $\mathrm{O}_{3}$ can further lead to changes in temperature and ultimately in atmospheric dynamics, both of which are important to the global climate [see, e.g., World Meteorological Organization $(W M O), 2007$, and references within].

\section{Detailed Summary of Earlier Study}

[8] Figure 1 provides context from the earlier work [Rodger et al., 2007] used in the current study. Rodger et al. [2007] made use of September 2005 measurements from subionospheric VLF transmissions collected by the AARDDVARK network [Clilverd et al., 2009b] to determine the precipitation flux of $L \sim 3$ energetic electrons from the radiation belts into the atmosphere. Across the time period August-September 2005 there was a series of major geomagnetic disturbances, two of which occurred during two solar proton events in midSeptember. At the highest latitudes, the solar proton events 

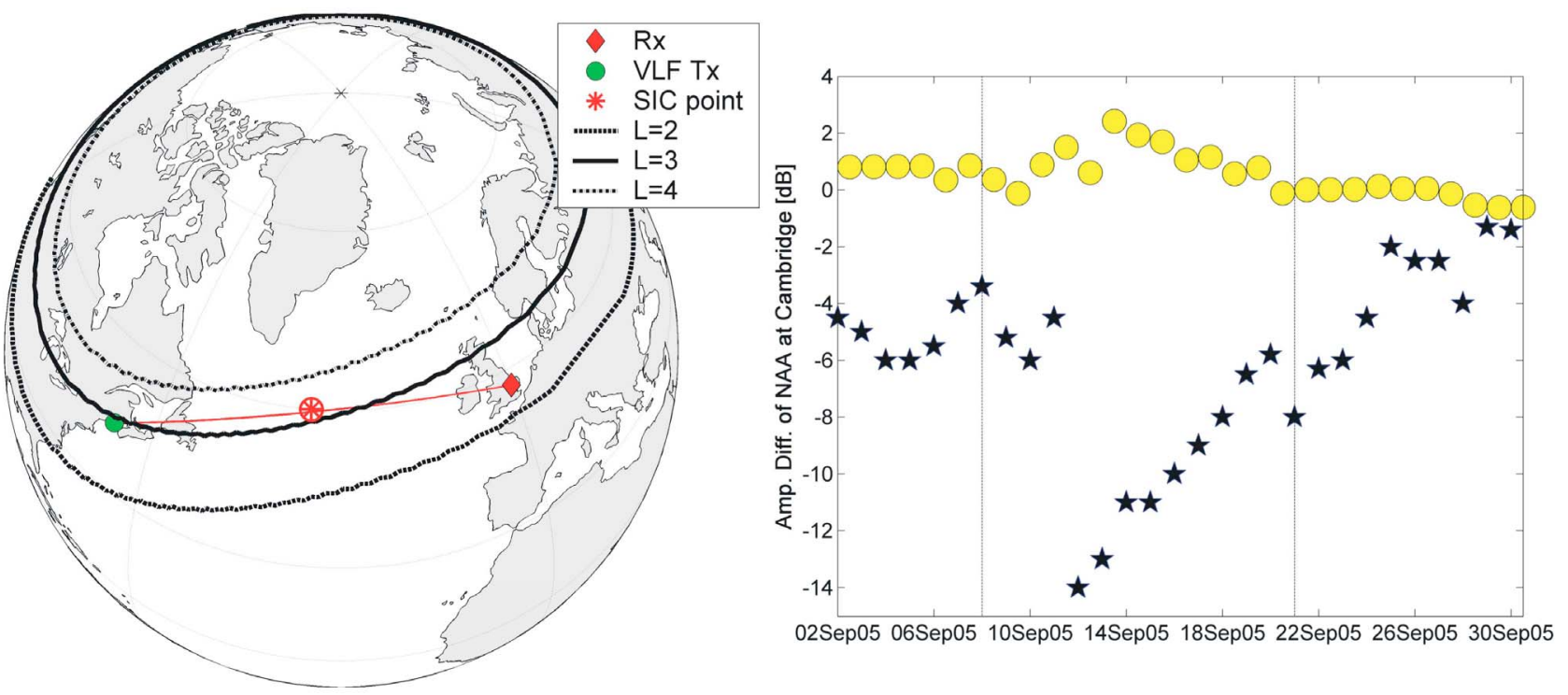

Figure 1. (left) Map showing the location of the transmitter NAA, the VLF receiver, and the SIC modeling location. This map also indicates the great circle propagation path between the transmitter and receiver, as well as a number of fixed $L$ shell contours. (right) Difference between the quiet time received amplitudes and those during September 2005 for the transmitter NAA observed at Cambridge for midday (yellow circles) and midnight (dark stars), following Rodger et al. [2007].

dominate any other atmospheric ionization sources [Rodger et al., 2006, 2007]. However, the geomagnetic field "filters" the access of solar protons [Störmer, 1930] so that even during very large geomagnetic storms there is little influence from solar protons on the atmosphere at $L=3$ [Rodger et al., 2006; Clilverd et al., 2007b]. Rodger et al. [2007] earlier reported large changes in the received amplitudes in transmissions from the U.S. Navy VLF transmitter with call sign NAA $\left(24.0 \mathrm{kHz}, 44.6^{\circ} \mathrm{N}, 67.3^{\circ} \mathrm{W}, L=3\right)$ on propagation along the roughly $L=3$ path to the AARDDVARK receiver in Cambridge, England $\left(52.3^{\circ} \mathrm{N}, 0^{\circ} \mathrm{E}, L=2.3\right)$. These authors argued that the amplitude changes reported by the Cambridge receiver were best explained by energetic electron precipitation from the radiation belt into the atmosphere along this path. Figure 1 (left) indicates the location of the transmitter NAA (circle), the Cambridge receiver (diamond), and the Great Circle Path between them. Figure 1 (right) shows the midday (yellow circle) and midnight (dark star) amplitude changes reported from the Cambridge receiver throughout September 2005. The changes are reported relative to the "Quite Day Curve" (QDC) level; that is, the difference in the received amplitude relative to undisturbed conditions (Figure 2). The ionospheric forcing from the energetic electron precipitation leads to a $2.4 \mathrm{~dB}$ maximum increase in the amplitude of NAA observed at Cambridge at midday, but a $14 \mathrm{~dB}$ decrease in the same quantity observed at midnight, both around 12-13 September 2005, shortly after a large geomagnetic storm $\left(D_{s t}\right.$ decreased to $\left.\sim 130 \mathrm{nT}\right)$. Note that the Cambridge subionospheric observations are disturbed from the start of our observations in early September 2005. A geomagnetic storm in late August 2005 boosted the radiation belt fluxes $\sim 1000$ times above ambient conditions [Rodger et al., 2007, Figure 2], with satellite observed fluxes decaying away through atmospheric precipitation, leading to enhanced ionization levels and hence disturbed subionospheric propagation. The slow return of the Cambridge subionospheric observations to near quiet levels (Figure 1) was seen to be consistent with the satellite observed flux levels returning toward ambient levels, with the mid-September storm flux enhancement taking several weeks to decay through precipitation into the atmosphere. The Rodger et al. study concluded that the principal driver for this precipitation was waveparticle interactions between the radiation belt electrons and plasmaspheric hiss. Plasmaspheric hiss is a broadband, structureless, extremely low-frequency (ELF) electromagnetic emission, which occurs in the frequency range from $\sim 200 \mathrm{~Hz}$ to $2 \mathrm{kHz}$. This natural whistler mode emission is typically observed inside Earth's plasmasphere or in detached plasma regions [see Hayakawa and Sazhin, 1992; Bortnik et al., 2009]. Plasmaspheric hiss is generally recognized as responsible for creating and maintaining the "slot region" between the inner and outer radiation belts [e.g., Lyons and Thorne, 1973], and the decay of outer belt energetic electrons after geomagnetic storms [Meredith et al., 2006; Rodger et al., 2007].

[9] Rodger et al. [2007] described how a simple chemical model (extended from Rodger et al. [1998]) could be combined with a subionospheric propagation model (LWPC; see Ferguson and Snyder [1990]) to determine the nature of the ionization changes along the transmitter-receiver path, and hence the precipitation flux of electrons into the atmosphere. This required information on the energy spectrum of precipitating electrons, which was provided by instruments onboard the Combined Release and Radiation Effects Satellite (CRRES) and DEMETER satellite. The Rodger et al. [2007] study showed that the storm time electron spectra observed at $L \approx 3$ were consistent between the observations made by these two spacecraft, even though CRRES measures near the top of the 


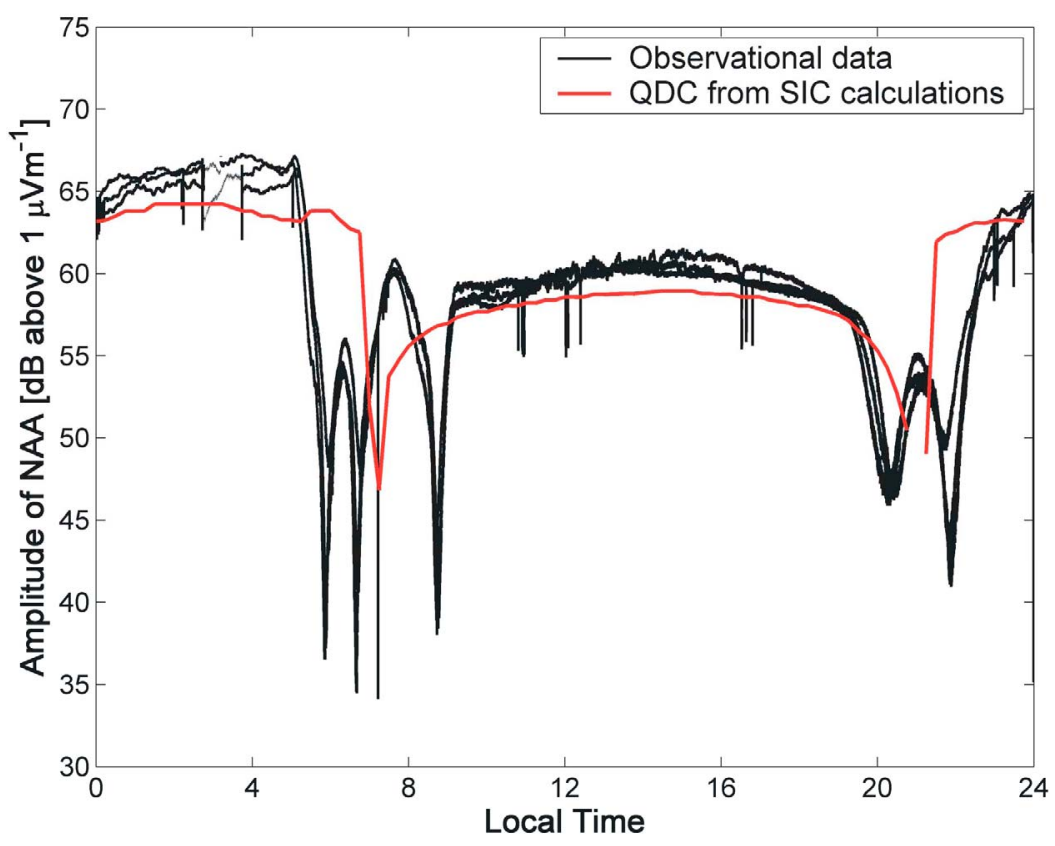

Figure 2. Example of the undisturbed variation in the observed amplitude of the transmitter NAA, measured in Cambridge during September 2008, for comparison with the disturbed period in September 2005. Overplotted is the QDC produced by running the SIC control-run electron densities through the LWPC propagation model.

geomagnetic field lines and DEMETER observes the drift loss cone from low-Earth orbit, and the storm events were separated in time by $\sim 25$ years.

\section{Experimental Observations and Modeling Tools}

[10] In the current study our goal is to examine the significance of the Rodger et al. [2007] reported electron precipitation fluxes to the chemistry of the neutral atmosphere. We will therefore expand upon the earlier modeling work of Rodger et al. [2007], and apply the precipitating fluxes to the Sodankylä Ion and Neutral Chemistry (SIC) model to determine the chemical changes caused by electron precipitation. As the altitude of the electron precipitation-produced ionization changes is determined by the electron energy spectrum, we use DEMETER to determine the spectral variation, rather than rely on a constant storm-time spectrum as in the work of Rodger et al. [2007]. Our study relies upon experimental measurements from AARDDVARK and DEMETER, combined with modeling from LWPC and SIC. We therefore describe each one of these in turn.

\subsection{AARDDVARK}

[11] The Cambridge receiver site is part of the AntarcticArctic Radiation-Belt Dynamic Deposition VLF Atmospheric Research Konsortia (AARDDVARK) [Clilverd et al., 2009b]. More information on AARDDVARK can be found at the Konsortia website: http://www.physics.otago.ac.nz/space/ AARDDVARK_homepage.htm. The Cambridge receiver in September 2005 was an AbsPAL [Thomson et al., 2005], but is now an UltraMSK [Clilverd et al., 2009b]. Both receiver types log the amplitude and phase of the transmis- sions broadcast from the large communications transmitter NAA, located on the east coast of the United States (Figure 1).

[12] Figure 2 shows examples of the undisturbed variation (black lines) in the observed amplitude of transmissions from NAA, measured in Cambridge during 10-14 September 2008. We use the September 2008 data to represent the "quiet" propagation conditions which would have existed in September 2005, if there was no precipitation present. Owing to the normally dominant influence of the Sun on $D$ region ionization rates, the daytime period $(\sim 0930-1900$ LT) in Figure 2 is less variable than nighttime ( 2300-0500 LT). The structure seen in the received signal between these times is due to sunrise/sunset modal inference, which is particularly strong for mixed day/night paths [Clilverd et al., 1999]. The red line Figure 2 shows the diurnal amplitude variation produced by running the SIC control-run electron densities, determined from the midpoint on the NAA-Cambridge path, through the LWPC propagation model. The details of the models and uses will be discussed later in section 3 .

\subsection{DEMETER}

[13] DEMETER is the first of the Myriade series of microsatellites developed by the Centre National d'Etudes Spatiales for low-cost science missions, and was placed in a circular Sun-synchronous polar orbit at an altitude of $710 \mathrm{~km}$ at the end of June 2004. Electron flux and energy spectra observations are provided by DEMETER's IDP instrument, although we do not include measurements made inside the South Atlantic Magnetic Anomaly. The IDP spectrometer [Sauvaud et al., 2006] is unusual in that it has very highenergy resolution; in its normal "survey" mode the instrument measures electron fluxes in the drift loss cone with energies from $70 \mathrm{keV}$ to $2.34 \mathrm{MeV}$ using 128 energy channels. 


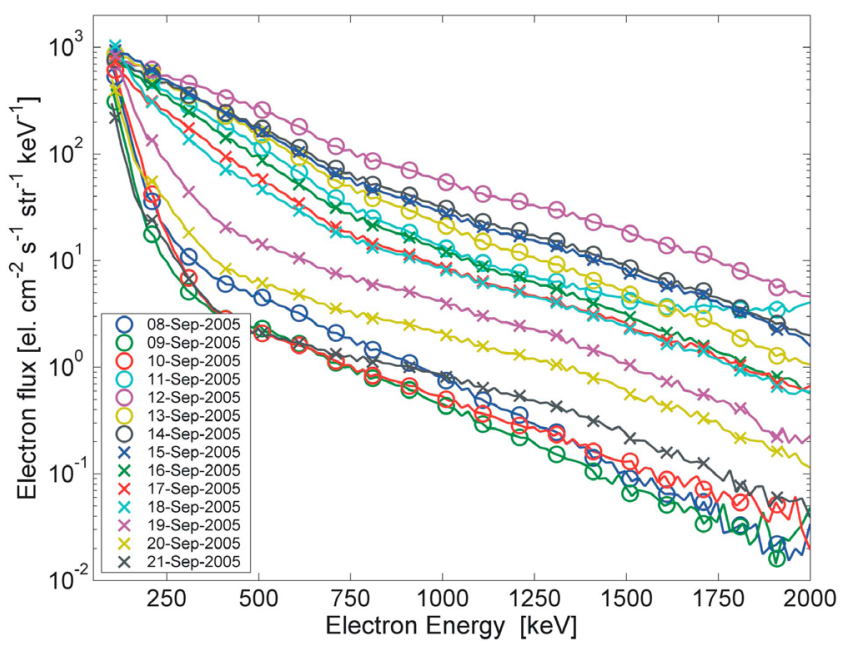

Figure 3. Daily averaged DEMETER-measured drift loss cone electron energy spectra at $L=3.2$ during the period considered in this study.

[14] Figure 3 shows the daily average DEMETERmeasured drift loss cone electron energy spectra at $L=3.1-$ 3.3 from 8 to 21 September 2005. The flux and energy spectra are very similar at the beginning and end of this time period, but become both larger and harder owing to the midSeptember geomagnetic storm. The highest fluxes are observed on the day after the peak of the geomagnetic storm. Although DEMETER provides us with a good measure of the electron fluxes in the drift loss cone, this does not represent the electron precipitation flux into the atmosphere for most of the world, as the drift loss cone precipitates into the South Atlantic where the magnetic field strengths are lower in the South Atlantic Anomaly. Hence we need to determine the electron precipitation flux through other means, such as by using the AARDDVARK data.

\subsection{LWPC}

[15] Mesospheric ionization effects on VLF/LF wave propagation can be modeled using the Long Wave Propagation Code (LWPC; see Ferguson and Snyder [1990]). LWPC models VLF signal propagation from any point on Earth to any other point. Given electron density profile parameters for the upper boundary conditions, LWPC calculates the expected amplitude and phase of the VLF signal at the reception point. LWPC can be used to investigate changes in the lower ionosphere as long as the induced changes to the electron density altitude profiles are known. For this purpose we use the electron density altitude profiles produced by a simple ionospheric electron model based on that given by Rodger et al. [1998] but improved through testing against the Sodankylä Ion and Neutral Chemistry model as reported in the work of Rodger et al. [2007]. The SIC model is too complex for exploring the most likely precipitation flux magnitudes with LWPC, as the computation time is relatively high.

\subsection{Sodankylä Ion and Neutral Chemistry model}

[16] The Sodankylä Ion and Neutral Chemistry (SIC, version 6.10) model is a 1-D ion and neutral chemistry model designed for ionospheric $D$ region studies. The model solves concentrations of 65 ions, including 36 positive ions and 29 negative ions, as well as 16 minor neutral species at altitudes across $20-150 \mathrm{~km}$. A detailed overview of the model is given in the work of Verronen et al. [2005], but we summarize some key features here to provide background for this study.

[17] Several hundred chemical and photochemical reactions are included in the model. External forcing from solar radiation (1-422.5 nm), electron and proton precipitation, and galactic cosmic radiation (GCR) is taken into account. The solar flux is calculated with the Solar Irradiance Platform (previously SOLAR2000) model (version 2.35) [Tobiska et al., 2000]. The model includes a vertical transport scheme, as described by Chabrillat et al. [2002], which takes into account molecular and eddy diffusion. Within the transport code the molecular diffusion coefficients are calculated according to Banks and Kockarts [1973]. Eddy diffusion coefficient profile can be varied using the parameterization given by Shimazaki [1971]. Vertical transport and chemistry are advanced in $15 \mathrm{~min}$ intervals (with exponentially increasing time steps within each interval) during which the model background atmosphere and all external forcing are kept constant.

[18] In the current study the SIC model is run for two locations. We initially perform the calculations at the location $\left(54^{\circ} \mathrm{N}, 35^{\circ} \mathrm{W}\right)$ marked on Figure 1 (i.e., the halfway point on the NAA-CAM path) following Rodger et al. [2007]. As discussed later, we also extend the model calculations to a second location at a high latitude $\left(70^{\circ} \mathrm{S}, 90^{\circ} \mathrm{W}\right)$. Owing to the relatively high-latitude path, a background drizzle of particle precipitation is included in the SIC calculations, which is necessary to reproduce the quiet time subionospheric observations. Similar background precipitation has been applied in earlier studies [e.g., Clilverd et al., 2006a] for the same reasons. The SIC model was then used to produce a control electron density profile with no additional electron precipitation sources. The time-varying electron densities from the control model run were fed into LWPC to produce a SIC modeled quiet time curve for VLF propagation, plotted in red in Figure 2. The agreement between the SIC modeled quiet time curve (red line) and the observed data (black lines) is very good, particularly given the results for a single modeling point are being taken to represent the entire $(\sim 4,800 \mathrm{~km})$ transmitter-receiver propagation path. The differences between the SIC model and the observed data are smaller than the natural background variability across the solar cycle [Thomson and Clilverd, 2000], and are similar to the day to day variation ( 1.5 dB; see Thomson [1993]).

\subsection{Summary}

[19] The fundamental structure of our current study is as follows. First we use the daily electron energy spectra observed by DEMETER to establish the ionospheric electron density changes expected for a range of possible precipitation flux magnitudes, using the simple ionospheric chemistry model described by Rodger et al. [2007]. These ionospheric electron density changes are fed into the LWPC subionospheric propagation code, to determine the change in the received amplitude of transmissions from NAA to Cambridge for each magnitude of EEP and both day and night ionospheric conditions. By comparing the calculated NAA-Cambridge amplitude changes with those observed, nighttime and daytime electron precipitation flux magnitudes are determined for each day. In order to check the validity of our approach, 


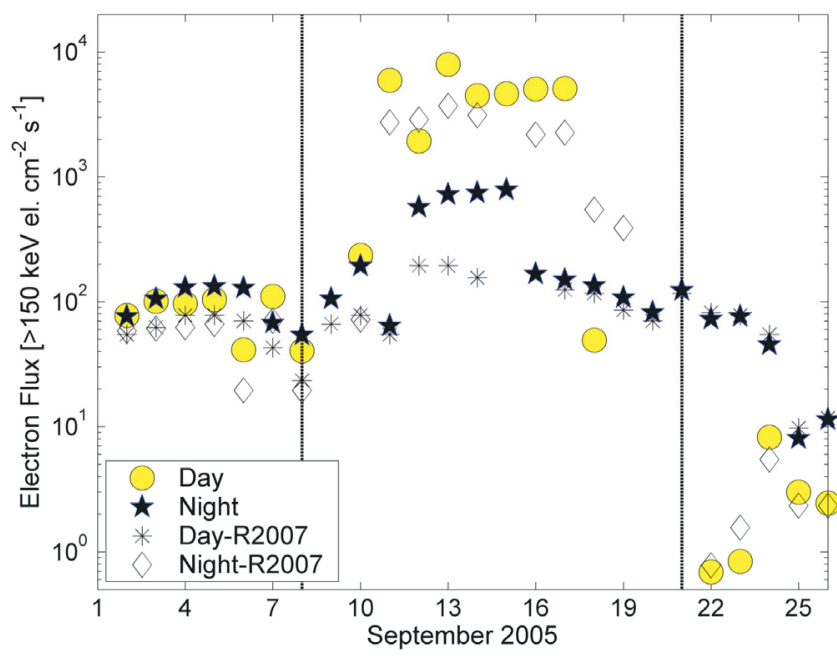

Figure 4. Time variation of the $>150 \mathrm{keV}$ electron flux precipitated into the atmosphere, determined for midday (yellow circles) and midnight (dark stars) using the NAA amplitude differences received at Cambridge (see Figure 1, right). The EEP magnitude values from of Rodger et al. [2007, Figure 8] (R-2007) have been superimposed for comparison.

ionization rates determined from the flux magnitudes are input to the Sodankylä Ion and Neutral Chemistry, and the resulting ionospheric electron number density profiles fed back into LWPC to ensure reasonable agreement with the experimental data. Finally the output of the SIC model is examined to consider the significance of this particular period of electron precipitation to neutral atmospheric chemistry.

\section{Determination and Testing of Precipitation Fluxes}

[20] The approach of Rodger et al. [2007] was applied to determine the precipitation fluxes into the atmosphere for the time period 2-26 September 2005, with the appropriate DEMETER energy spectra (Figure 3). This leads to Figure 4, showing the time variation of the $>150 \mathrm{keV} L=3.2$ electron flux precipitated into the atmosphere, determined from the time-varying amplitude differences of NAA received at Cambridge shown in Figure 1 (right) combined with modeling (LWPC + the simple ionospheric electron model). As before, midday values are represented by yellow circles and midnight by dark stars. Figure 4 should be contrasted with Rodger et al. [2007, Figure 8], who followed the same process but with a fixed storm-time energy spectrum. The EEP magnitude values from Rodger et al. [2007, Figure 8] have been superimposed onto Figure 4 for comparison with the earlier work. The fundamental pattern in the variation is similar, although there are differences in the $>150 \mathrm{keV}$ electron flux values. The peak precipitated fluxes of $>150 \mathrm{keV}$ electrons have increased from $3500 \mathrm{el} . \mathrm{cm}^{-2} \mathrm{~s}^{-1}$ at midday to $8000 \mathrm{el}$. $\mathrm{cm}^{-2} \mathrm{~s}^{-1}$ and from $185 \mathrm{el} . \mathrm{cm}^{-2} \mathrm{~s}^{-1}$ at midnight to $800 \mathrm{el}$. $\mathrm{cm}^{-2} \mathrm{~s}^{-1}$ because of differences in the energy spectrum used from day-to-day, rather than the fixed spectra used previously. The daytime precipitation fluxes shown in Figure 4 lead to ionospheric ionization rates which are similar to those predicted by Spjeldvik and Thorne [1975b, Figure 3] for $L=4$ when considering plasmaspheric hiss-driven precipitation after a geomagnetic storm [Spjeldvik and Thorne, 1975a], although our nighttime precipitation levels are significantly lower. We note that this paper suggested an examination of subionospheric VLF data in conjunction with satellite measurements of precipitating electron and plasmaspheric hiss, as undertaken in the current study.

[21] Owing to the SIC model not including any horizontal transport and having limited vertical transport description and therefore not being able to present variations related to transport in the atmosphere taking place in the time scales of several days, the model runs were limited to the time period of 8-21 September 2005. This period is indicated by the dotted lines in Figures 1 and 4. This includes the large increase in precipitation fluxes around the time of the mid-September storm, and much of the gradual recovery toward undisturbed conditions, and thus should capture the time variability in the ionization-produced chemical changes, if not their transport.

[22] These electron precipitation fluxes were applied to the SIC model, and the electron number density profiles produced by SIC were fed back into LWPC to test the accuracy of the flux estimates in Figure 4. In order to input the midday and midnight precipitation flux values into the SIC model, these need to be applied to the entire 24 hour day. In order to extend Figure 4 to all local times, we have considered the "normal" local time variation of plasmaspheric hiss intensity reported after geomagnetic disturbances [Meredith et al., 2004, Figure 3], as this will modulate the precipitation magnitude [Rodger et al., 2007]. From this study we argue that the "plasmaspheric hiss driver" will lead to midday-like precipitation conditions from 0500-1759 MLT, and midnight-like from 1800-0459 MLT. We assume that there is a 2 hour transition region from daytime to nighttime, where we linearly ramp the ionization rates. This produced the ionization rate variation shown in Figure 5, with the highest ionization rates of $10^{2}$ electrons $\mathrm{cm}^{-3} \mathrm{~s}^{-1}$ occurring at $\sim 73 \mathrm{~km}$ on 13 September 2005.

[23] Figure 6 shows the LWPC calculated differences in the amplitude of NAA received at Cambridge (open circles and stars) using the SIC modeled electron density profiles for the precipitation flux values reported in Figure 4. These calculations are contrasted with the experimentally observed NAA amplitude differences (yellow circles and dark stars), taken from Figure 1. In most cases there is a very strong agreement between the experimentally observed amplitude differences and those predicted by the SIC modeling. The most significant difference is during the nighttime period of 12-15 September 2005 , where there is a $\sim 5 \mathrm{~dB}$ disagreement between the SIC modeling and the observations. A straightforward approach using the simple chemistry model and LWPC shows that the amplitude response is very sensitive to the precipitation flux for these conditions, and that a small $(\sim 25-35 \%)$ decrease in the precipitation fluxes will lead to this magnitude of change. At these time periods there could be a $\sim 25-35 \%$ decrease in atmospheric ionization rates, which would produce roughly $25-35 \%$ less $\mathrm{NO}_{x}$ and $\mathrm{HO}_{x}$ production. As our goal is to estimate the significance of the precipitating fluxes to the neutral atmosphere, Figure 6 suggests that we have a sufficiently accurate set of modeling tools and approaches to represent the precipitation-driven ionization levels, which 


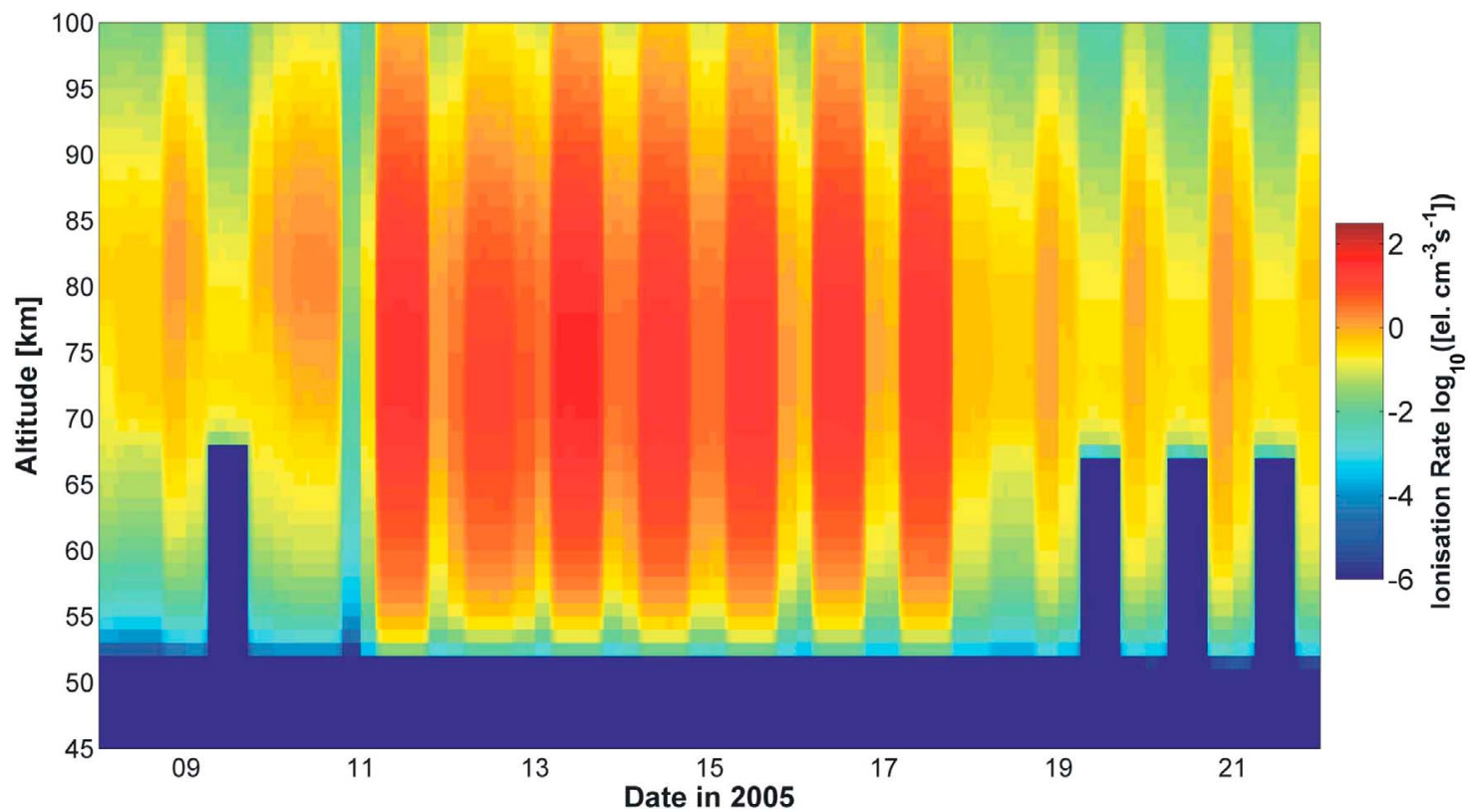

Figure 5. Time variation of the atmospheric ionization rate caused by the energetic electron precipitation rates shown in Figure 4.

can then be used to determine the effect on the neutral atmosphere.

\section{Effect of Precipitation on the Neutral Atmosphere}

[24] The SIC modeling used to establish the $>150 \mathrm{keV}$ electron precipitation fluxes given in Figure 4 also contains information on the effect of this precipitation on the neutral atmosphere. Figure 7 shows the changes in $\mathrm{NO}_{x}\left(\mathrm{NO}+\mathrm{NO}_{2}\right)$ due to the precipitating particles. Figure 7 (left) presents the variation in absolute number density in $\mathrm{mol} \mathrm{cm}{ }^{-3}$, while Figure 7 (right) shows the percentage changes relative to the control run. The in situ production of $\mathrm{NO}_{x}$ due to the energetic particle precipitation makes a more significant increase in the $\sim 65-85 \mathrm{~km}$ altitude range, with an increase of a factor of 56 relative to undisturbed conditions. Such an increase appears to be roughly similar in relative magnitude to that from relative electron precipitation as reported by Clilverd et al. [2009a, Figure 5]. The $\mathrm{NO}_{x}$ increase builds up primarily across the time span when the $>150 \mathrm{keV}$ electron precipitation fluxes peak in Figure 4, and then start to recover owing to photodissociation.

[25] $\mathrm{NO}_{x}$ and $\mathrm{HO}_{x}$ increases caused by energetic particle precipitation have been associated with in situ ozone loss in the polar middle atmosphere [Seppälä et al., 2006], particularly during Solar Proton Events which lead to very large increases in ionization in the upper-stratosphere-mesosphere region [e.g., Clilverd et al., 2005, Figure 3; Verronen et al., 2005, Figures 1 and 3]. However, in the case studied here there is an essentially insignificant level of ozone loss as shown in Figure 8 (left). For most of the forcing period, the $\mathrm{O}_{3}$ decreases are at the $0.5-1 \%$ level across $65-85 \mathrm{~km}$ altitudes, with short-lived decreases of up to $2.5-3.5 \%$. These occur at dawn and are associated with short-lived increases in $\mathrm{HO}_{x}$ $\left(\mathrm{HO}+\mathrm{HO}_{2}\right)$ (not shown). Figures 7 and 8 (left) demonstrate an important point concerning the production of $\mathrm{NO}_{x}$ in the mesosphere and upper stratosphere and its relative importance to stratospheric ozone in this case. For the September 2005 geomagnetic storm we have considered here, the electron precipitation occurs into a midlatitude atmospheric location during late summer-early autumn. Thus while the relative increases in $\mathrm{NO}_{x}$ appear to be large when contrasted with earlier studies which have reported large stratospheric $\mathrm{O}_{3}$ decreases associated with the $\mathrm{NO}_{x}$ increases and their subsequent descent to the stratosphere [e.g., Jackman et al., 2008], these took place at polar latitudes during the winter season when $\mathrm{NO}_{x}$ loss through photodissociation is ineffective. For our midlatitude September case, the affected atmosphere is still sunlit for
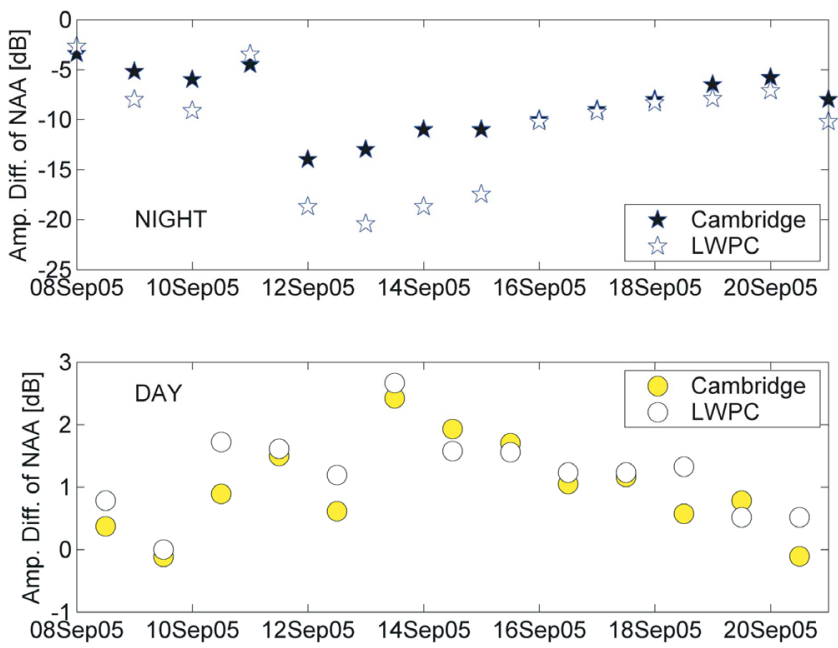

Figure 6. Comparison between the NAA amplitude differences determined from the electron densities calculated using the precipitation forced SIC model and the experimental observations (i.e., Figure 1, right). 

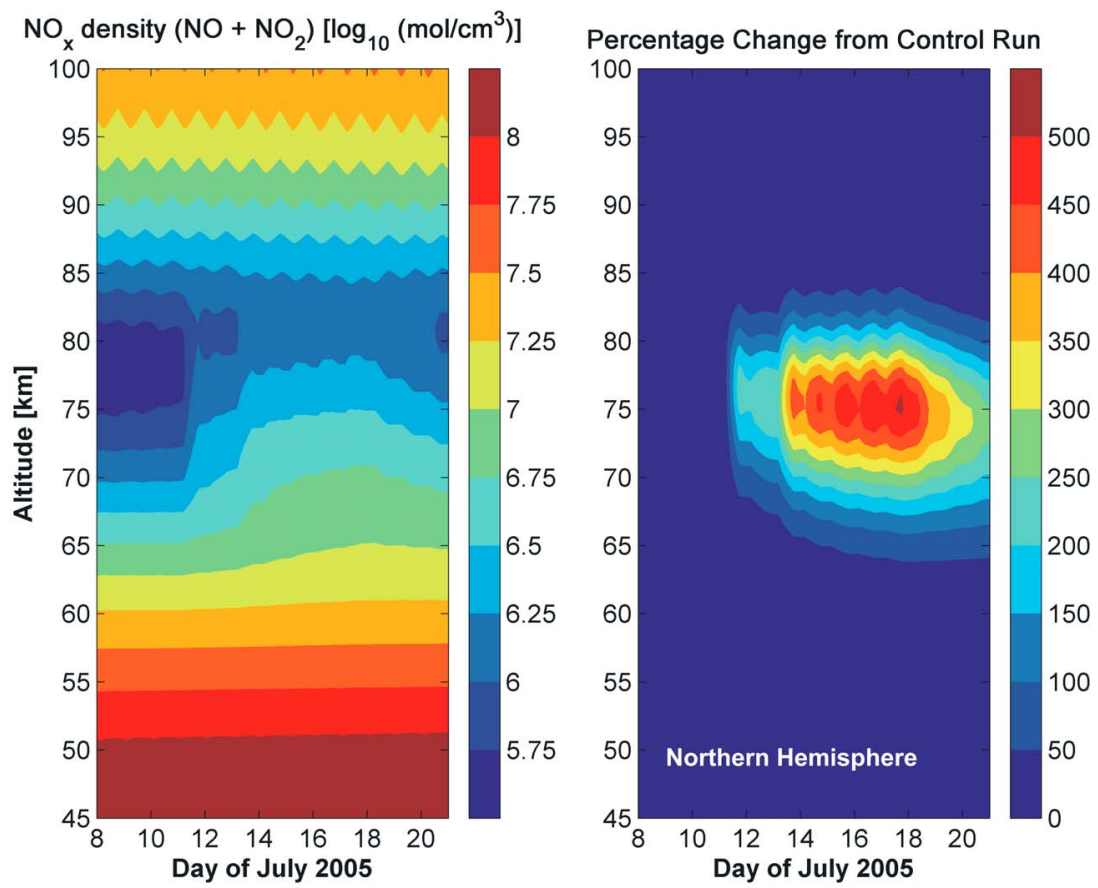

Figure 7. SIC model calculated changes in $\mathrm{NO}_{x}\left(\mathrm{NO}+\mathrm{NO}_{2}\right)$, when the model is driven by the $>150 \mathrm{keV}$ electron precipitation fluxes given in Figure 4. (left) The varying $\mathrm{NO}_{x}$ number density. (right) The percentage changes relative to the control run.

significant fractions of the day. This not only destroys $\mathrm{NO}_{x}$ but would also acts as a restoring force for stratospheric $\mathrm{O}_{3}$ as photodissociation of $\mathrm{O}_{2}$ drives the production of atomic oxygen, which in turn leads to $\mathrm{O}_{3}$ production through the reaction $\mathrm{O}_{2}+\mathrm{O}+\mathrm{M} \rightarrow \mathrm{O}_{3}+\mathrm{M}$. On the basis of these previous studies, this level of electron precipitation driven $\mathrm{NO}_{x}$ production could have led to significant indirect stratospheric ozone loss, had it occurred during the winter inside the polar vortex [Turunen et al., 2009].

[26] Strong interhemispheric differences in the response to particle precipitation have been demonstrated before [e.g.,
Jackman et al., 2005a; López-Puertas et al., 2005; Seppälä et al., 2008], particularly when considering solar proton events which will lead to near-identical ionization rate increases in both hemispheres, and thus provide an excellent test in the differing responses in the neutral chemistry to seasonal differences, particularly those due to solar illumination. The electron precipitation considered in the case study, affecting the midlatitudes during late summer-early autumn does not lead to significant ozone responses, and is unlikely to result in significant stratospheric changes owing to the absence of a polar vortex. We therefore consider the maximum possible in
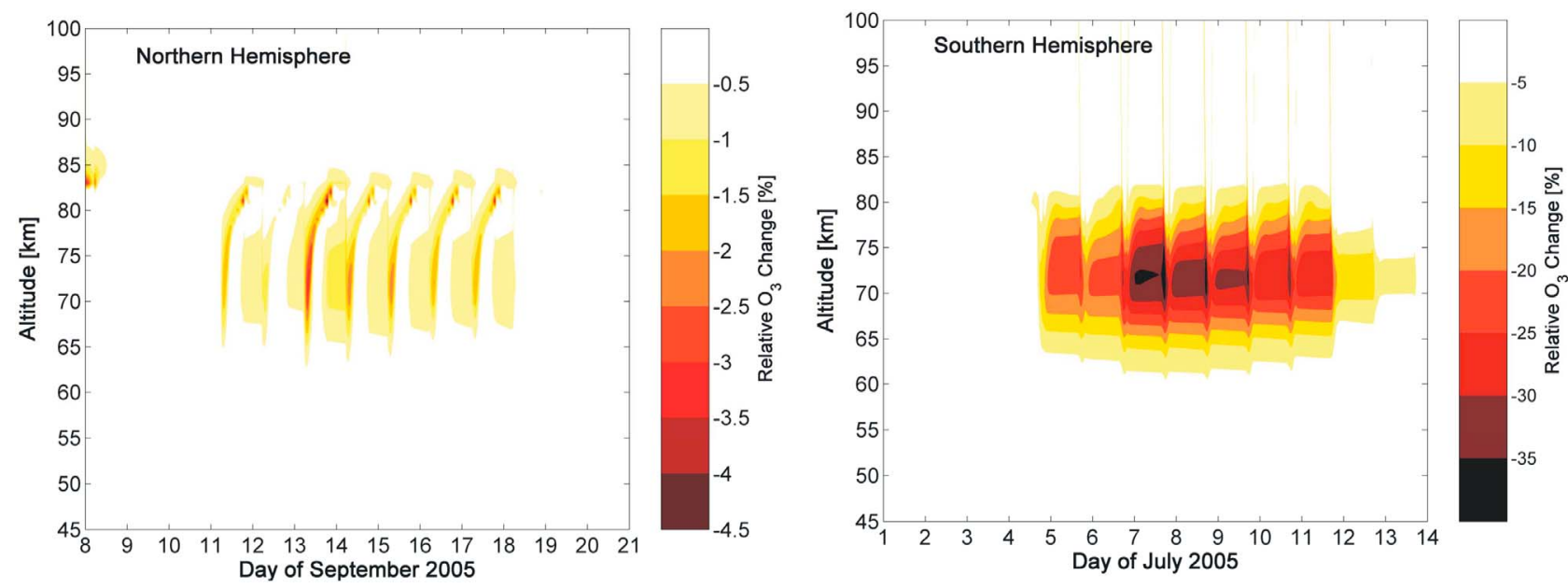

Figure 8. SIC calculated relative changes in $\mathrm{O}_{3}$, when the model is driven by the $>150 \mathrm{keV}$ electron precipitation fluxes given in Figure 4. (left) The relative ozone decreases in the Northern Hemisphere. (right) The contrasting the Southern Hemisphere case, with limited solar illumination (i.e., winter time), linked to the chemical changes associated with Figure 9. 

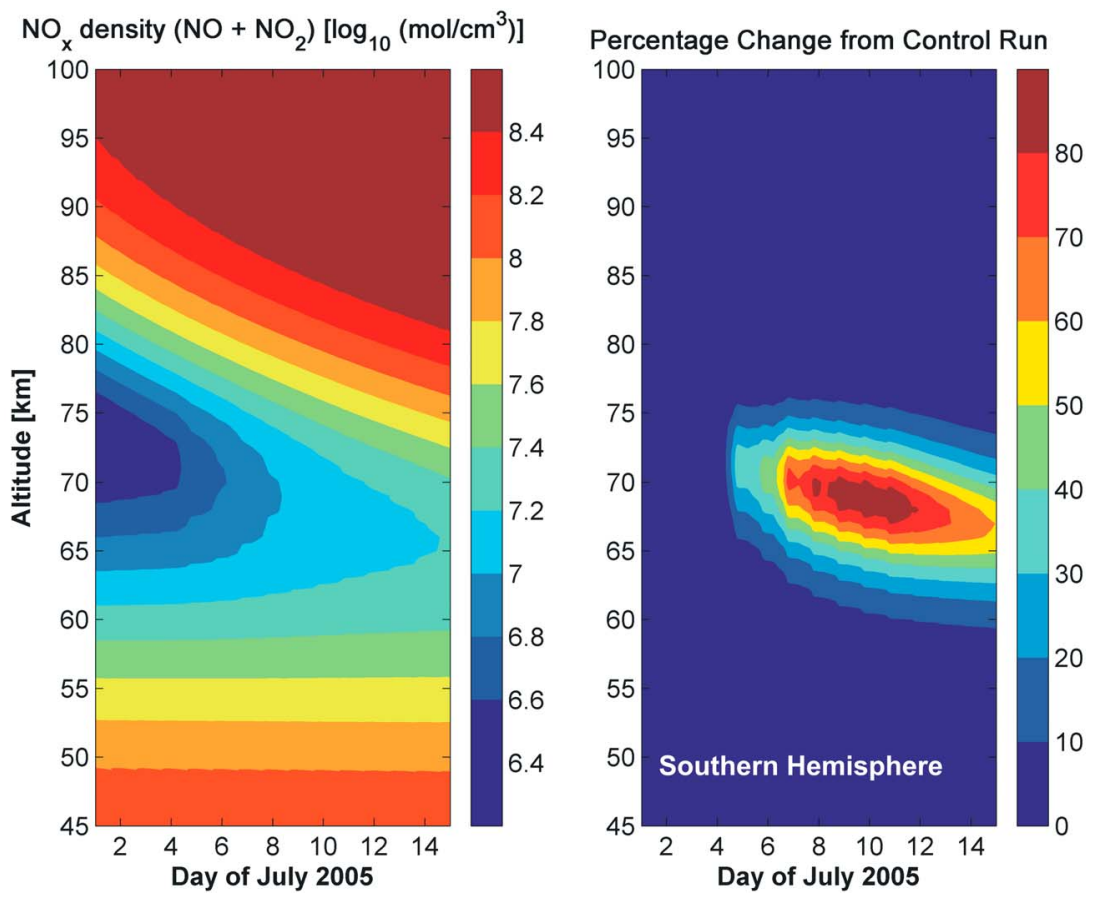

Figure 9. Southern Hemisphere wintertime $\mathrm{NO}_{x}$ changes in the same format as Figure 7. These SIC model calculations examine the maximum in situ impact that could be caused by the precipitation fluxes determined in this study.

situ effect this electron precipitation event might cause, assuming the Figure 4 precipitation flux magnitude and time variation impacted into the polar atmosphere during the winter when there is no sunlight. As our flux magnitudes were determined for $L=3.2$, we retain this geomagnetic coordinate but shift to the highest possible latitude. This location corresponds to the Southern Hemisphere, where we select the location at $\left(70^{\circ} \mathrm{S}, 90^{\circ} \mathrm{W}\right)$, and consider midwinter times in July 2005. The ionization rates are as determined for the northern hemisphere situation, but with the first day of ionization in the Southern Hemisphere on 1 July 2005 corresponding to 8 September 2005 in the Northern Hemisphere. Figure 9 presents the Southern Hemisphere wintertime $\mathrm{NO}_{x}$ changes in the same format as Figure 7. The absolute $\mathrm{NO}_{x}$ changes are $\sim 35 \%$ larger in the Southern Hemisphere relative to the Northern Hemisphere, and persist for longer owing to the lack of photodissociation. However, the relative changes are very different between the hemispheres, reflecting the very strong influence of seasonal and temporal variation. There is much more $\mathrm{NO}_{x}$ present in the winter polar mesosphere $(\mathrm{SH})$ when compared with the nonwinter midlatitude (NH) case, as $\mathrm{NO}_{x}$ is not effectively photodissociated in the $\mathrm{SH}$ location. As a result the magnitude of the relative increase is very different between the two hemispheres (a maximum increase of $90 \%$ in the $\mathrm{SH}$ relative to an increase of $\sim 450 \%$ in the $\mathrm{NH}$ ), and at different altitude levels.

[27] The relative $\mathrm{O}_{3}$ decreases are much larger for the Southern Hemisphere case, with initial $\mathrm{HO}_{x}$ induced $\mathrm{O}_{3}$ depletion being 5-10 times stronger at $65-80 \mathrm{~km}$. Furthermore, while the $\mathrm{NH} \mathrm{O}_{3}$ decreases were due to in situ $\mathrm{HO}_{x}$ enhancements and no indirect effects in the stratosphere are expected, the long-lived $\mathrm{NO}_{x}$ present in the winter $\mathrm{SH}$ is potentially important to the loss of stratospheric $\mathrm{O}_{3}$ through descent.
[28] Figure 8 emphasizes the importance of illumination (solar zenith angle) conditions on the effectiveness of particle precipitation to lead to significant in situ neutral atmosphere changes. Figure 8 shows how the precipitation of energetic electrons from the radiation belts, can, depending on the season in which the storm and subsequent precipitation occurs, result in significant in situ mesospheric $\mathrm{O}_{3}$ changes (due to seasonal asymmetries in background mesospheric $\mathrm{HO}_{x}$ production; see Jackman et al. [2008]). The magnitude, time scales, and altitudes of these changes are rather similar to those calculated by the SIC model for large Solar Proton Events [Verronen et al., 2002, 2005], confirmed by experimental observations using the GOMOS satellite instrument [Verronen et al., 2005; Seppälä et al., 2006] and subionospheric VLF propagation measurements [Clilverd et al., $2005,2006 a]$. The scale size of these neutral atmosphere changes are not limited to studies relying upon the SIC model. The southern hemisphere EEP changes are also similar to those calculated for the SPEs which occurred in OctoberNovember 2003 (at least in the altitude range 65-85 km), confirmed by experimental observation [López-Puertas et al., 2005; Jackman et al., 2005a], and the calculations around the large SPEs which occurred over 2000-2003 [Jackman et al., $2005 \mathrm{~b}$. Such large $\mathrm{NO}_{x}$ increases produced in the middlemesosphere during the polar winter have been shown to further produce significant indirect $\mathrm{O}_{3}$ loss in the stratosphere [Randall et al., 2005; Seppälä et al., 2007; Randall et al., 2007], and might also be the link between geomagnetic activity and polar surface temperature pattern variability recently reported [Seppälä et al., 2009].

[29] It is, however, challenging to directly contrast the affect and significance of energetic electron precipitation and solar proton events. The later are major, though infrequent, 
space weather events with a typical duration of several days that impact the entire magnetic polar region [e.g., Rodger et al., 2006, Figure 8]. The ionization changes during an SPE can be significant down to $\sim 40 \mathrm{~km}$ altitude, while EEP tends to be most significant at considerably higher altitudes $(>65 \mathrm{~km})$. Solar proton events occur roughly 6 times/year, although most events are clustered after solar maximum [Shea and Smart, 1995], producing a rate of roughly 15 times/year [Gerontidou et al., 2002]. While energetic electron precipitation produces less significant ionization rates, as seen in Figure 5, they are considerably more common, and tend to last for longer time periods. Even during sunspot minima, the number of geomagnetic storms leading to significant radiation belt electron increases is $\sim 40$ /year, with each increase taking 10 days or more to recover through precipitation into the atmosphere [Clilverd et al., 2010, Figure 4]. As EEP is significantly more common than SPE, they may lead to a more significant indirect $\mathrm{O}_{3}$ loss in the stratosphere [Randall et al., 2005, 2007; Seppälä et al., 2007]. However, as EEP comes from the radiation belts, the majority of the precipitation is present in the outer parts of the magnetic poles (L 3-6), such that at least some of the precipitation will occur into the atmosphere located outside the polar vortex. Further research is required into the nature and significance of both processes. Initial modeling suggests that EEP may be climatically significant owing to longer-lasting changes in atmospheric chemistry [Langematz et al., 2005; Rozanov et al., 2005], albeit only representing the precipitation of auroral and medium energy electrons, while solar proton events do not appear to be [Jackman et al., 2009].

\section{Conclusions}

[30] The effect of "pumping up" the radiation belts during geomagnetic storms is translated to Earth by the loss (i.e., precipitation) of highly energized electrons into the middle and upper atmosphere $(30-90 \mathrm{~km})$. However, direct satellite observations of energetic electrons in the bounce loss cone are very rare. In this study we have improved upon earlier analysis of ground-based subionospheric radio wave observations to determine the time-varying precipitation flux of electrons into the atmosphere during and after a geomagnetic disturbance which occurred in September 2005. In the current study, the changing satellite-measured electron energy spectra were included in the modeling approach, in which a simple ionospheric chemistry model was combined with a subionospheric propagation model to predict the time-varying magnitude of the precipitation flux. In order to test the quality of this approach, these precipitation fluxes were then used as an input into the state-of-the-art Sodankylä Ion and Neutral Chemistry (SIC) model, which confirmed the precipitation flux estimates provided by the initial approach.

[31] We find that the precipitated fluxes of $>150 \mathrm{keV}$ electrons peaked during this storm period at midday on 13 September 2005 with a magnitude of $8000 \mathrm{el} . \mathrm{cm}^{-2} \mathrm{~s}^{-1}$, while the midnight flux peaks at $800 \mathrm{el} . \mathrm{cm}^{-2} \mathrm{~s}^{-1}$ on $15 \mathrm{Sep}-$ tember 2005 . The fluxes are $\sim 2-4$ times larger than reported in the work of Rodger et al. [2007], because of differences in the energy spectrum used from day to day, rather than the fixed spectrum used in that earlier study.

[32] The SIC model calculations were then used to examine the effect of this precipitation on the neutral atmosphere. For the Northern Hemisphere precipitation point considered first, we found large increases in $\mathrm{NO}_{x}(>300 \%)$ occurring in the altitude range $70-80 \mathrm{~km}$, and lasting for $\sim 5$ days. However, as the geomagnetic storm period in question occurred during late summer-early autumn, driving precipitation into a sunlit midlatitude location, the ozone decreases associated with the storm driven $\mathrm{HO}_{x}$ increases are small and short-lived. Had the storm occurred in a different season, it could have led to precipitation directly into the wintertime polar vortex, where the $\mathrm{NO}_{x}$ enhancements would be long-lived, and can potentially descent downward to the stratosphere leading to enhanced upper-stratospheric ozone loss. As a test, we repeated the SIC calculations for a $L=3.2$ location at the highest possible latitude (i.e., the southern polar region) during the midwinter season. This produced significant increases in both $\mathrm{NO}_{x}$ and $\mathrm{HO}_{x}$ at $65-70 \mathrm{~km}$ altitudes, resulting in significant in situ mesospheric ozone decreases, which are driven by the $\mathrm{HO}_{x}$ enhancements (decreases of $20 \%$ or more from $\sim 65-80 \mathrm{~km})$. The large $\mathrm{NO}_{x}$ increases, which in our simulation last beyond the modeling period, produced in the middle-mesosphere during the polar winter can be transported to lower altitudes and could within few weeks of the initial production lead to indirect $\mathrm{O}_{3}$ loss in the upper stratosphere, as well as provide a possible link between geomagnetic activity and polar surface temperature variability recently reported [Seppälä et al., 2009].

[33] Acknowledgments. C.J.R. would like to thank Jodie Salmond of Auckland for her support. C.J.R., M.A.C., and A.S. acknowledge the funding of the LAPBIAT2 program (contract RITA-CT-2006-025969) for supporting their time at SGO, where they worked on this manuscript in 2008 and 2009. The work of A.S. was supported by the EPPIC Marie Curie FP7 project (PIEF-GA-2009-237461). The work of J.A.S. and M.P. was supported by the Centre National d'Etudes Spatiales, while C.J.R. is a guest investigator inside the DEMETER program.

[34] Masaki Fujimoto thanks Miriam Sinnhuber and another reviewer for their assistance in evaluating this paper.

\section{References}

Alfonsi, L., et al. (2008), Probing the high latitude ionosphere from ground-based observations: The state of current knowledge and capabilities during IPY (2007-2009), J. Atmos. Sol. Terr. Phys., 70, 2293-2308, doi:10.1016/j.jastp.2008.06.013.

Banks, P. M., and G. Kockarts (Eds.) (1973), Aeronomy, vol. B, chap. 15, Academic, San Diego, Calif.

Barr, R., D. L. Jones, and C. J. Rodger (2000), ELF and VLF radio waves, J. Atmos. Sol. Terr. Phys., 62, 1689-1718, doi:10.1016/S1364-6826(00) 00121-8.

Bortnik, J., R. M. Thorne, and N. P. Meredith (2009), Plasmaspheric hiss overview and relation to chorus, J. Atmos. Sol. Terr. Phys., 71, 1636-1646, doi:10.1016/j.jastp.2009.03.023.

Brasseur, G., and S. Solomon (2005), Aeronomy of the Middle Atmosphere, 3rd ed., Springer, Dordrecht, Netherlands.

Callis, L. B., D. N. Baker, M. Natarajan, J. B. Blake, R. A. Mewaldt, R. S. Selesnick, and J. R. Cummings (1996), A 2-D model simulation of downward transport of $\mathrm{NO}_{\mathrm{y}}$ into the stratosphere: Effects on the 1994 austral spring $\mathrm{O}_{3}$ and $\mathrm{NO}_{\mathrm{y}}$, Geophys. Res. Lett., 23, 1905-1908, doi:10.1029/96GL01788

Chabrillat, S., G. Kockarts, D. Fonteyn, and G. Brasseur (2002), Impact of molecular diffusion on the $\mathrm{CO}_{2}$ distribution and the temperature in the mesosphere, Geophys. Res. Lett., 29(15), 1729, doi:10.1029/ 2002GL015309.

Clilverd, M. A., N. R. Thomson, and C. J. Rodger (1999), Sunrise effects on VLF signals propagating over a long north-south path, Radio Sci., 34, 939-948, doi:10.1029/1999RS900052.

Clilverd, M. A., C. J. Rodger, T. Ulich, A. Seppälä, E. Turunen, A. Botman, and N. R. Thomson (2005), Modeling a large solar proton event in the southern polar atmosphere, J. Geophys. Res., 110, A09307, doi:10.1029/2004JA010922. 
Clilverd, M. A., A. Seppälä, C. J. Rodger, N. R. Thomson, P. T. Verronen, E. Turunen, T. Ulich, J. Lichtenberger, and P. Steinbach (2006a), Modeling polar ionospheric effects during the October-November 2003 solar proton events, Radio Sci., 41, RS2001, doi:10.1029/2005RS003290.

Clilverd, M. A., C. J. Rodger, and T. Ulich (2006b), The importance of atmospheric precipitation in storm time relativistic electron flux drop outs, Geophys. Res. Lett., 33, L01102, doi:10.1029/2005GL024661.

Clilverd, M. A., C. J. Rodger, R. M. Millan, J. G. Sample, M. Kokorowski, M. P. McCarthy, T. Ulich, T. Raita, A. J. Kavanagh, and E. Spanswick (2007a), Energetic particle precipitation into the middle atmosphere triggered by a coronal mass ejection, J. Geophys. Res., 112, A12206, doi:10.1029/2007JA012395.

Clilverd, M. A., C. J. Rodger, T. Moffat-Griffin, and P. T. Verronen (2007b), Improved dynamic geomagnetic rigidity cutoff modeling: Testing predictive accuracy, J. Geophys. Res., 112, A08302, doi:10.1029/ 2007JA012410.

Clilverd, M. A., A. Seppälä, C. J. Rodger, N. R. Thomson, J. Lichtenberger, and P. Steinbach $(2007 \mathrm{c})$, Temporal variability of the descent of highaltitude $\mathrm{NO}_{X}$, J. Geophys. Res., 112, A09307, doi:10.1029/2006JA012085.

Clilverd, M. A., et al. (2008), Energetic electron precipitation during substorm injection events: High-latitude fluxes and an unexpected midlatitude signature, J. Geophys. Res., 113, A10311, doi:10.1029/ 2008JA013220.

Clilverd, M. A., A. Seppälä, C. J. Rodger, M. G. Mlynczak, and J. U. Kozyra (2009a), Additional stratospheric $\mathrm{NO}_{x}$ production by relativistic electron precipitation during the 2004 spring $\mathrm{NO}_{x}$ descent event, J. Geophys. Res., 114, A04305, doi:10.1029/2008JA013472.

Clilverd, M. A., et al. (2009b), Remote sensing space weather events: The AARDDVARK network, Space Weather, 7, S04001, doi:10.1029/ 2008SW000412.

Clilverd, M. A., C. J. Rodger, R. J. Gamble, T. Ulich, T. Raita, A. Seppala, J. C. Green, N. R. Thomson, J.-A. Sauvaud, and M. Parrot (2010), Ground-based estimates of outer radiation belt energetic electron precipitation fluxes into the atmosphere, J. Geophys. Res., doi:10.1029/ 2010JA015638, in press.

Cummer, S. A. (2000), Modeling electromagnetic propagation in the Earthionosphere waveguide, IEEE Trans. Antennas Propag., 48, 1420-1429, doi:10.1109/8.898776.

Elias, A. G., and M. Zossi de Artigas (2003), A search for an association between the equatorial stratospheric QBO and solar UV irradiance, Geophys. Res. Lett., 30(16), 1841, doi:10.1029/2003GL017771.

Ferguson, J. A., and F. P. Snyder (1990), Computer programs for assessment of long wavelength radio communications, Tech. Doc. 1773, Natl. Ocean Syst. Cent, San Diego, Calif.

Funke, B., M. López-Puertas, S. Gil-López, T. von Clarmann, G. P. Stiller, H. Fischer, and S. Kellmann (2005), Downward transport of upper atmospheric $\mathrm{NO}_{x}$ into the polar stratosphere and lower mesosphere during the Antarctic 2003 and Arctic 2002/2003 winters, J. Geophys. Res., 110, D24308, doi:10.1029/2005JD006463.

Gerontidou, M., A. Vassilaki, H. Mavromichalaki, and V. Kurt (2002), Frequency distributions of solar proton events, J. Atmos. Sol. Terr. Phys., 64, 489-496, doi:10.1016/S1364-6826(02)00004-4.

Grenfell, J. L., R. Lehmann, P. Mieth, U. Langematz, and B. Steil (2006), Chemical reaction pathways affecting stratospheric and mesospheric ozone, J. Geophys. Res., 111, D17311, doi:10.1029/2004JD005713.

Haigh, J. D., M. Blackburn, and R. Day (2005), The response of tropospheric circulation to perturbations in lower-stratospheric temperature, J. Clim., 18, 3672-3685, doi:10.1175/JCLI3472.1.

Hayakawa, M., and S. S. Sazhin (1992), Mid-latitude and plasmaspheric hiss: A review, Planet. Space Sci., 40, 1325-1338, doi:10.1016/00320633(92)90089-7.

Jackman, C. H., M. T. DeLand, G. J. Labow, E. L. Fleming, D. K. Weisenstein, M. K. W. Ko, M. Sinnhuber, and J. M. Russell (2005a), Neutral atmospheric influences of the solar proton events in October-November 2003, J. Geophys. Res., 110, A09S27, doi:10.1029/2004JA010888.

Jackman, C. H., M. T. DeLand, G. J. Labow, E. L. Fleming, D. K. Weisenstein, M. K. W. Ko, M. Sinnhuber, J. Anderson, and J. M. Russell (2005b), The influence of the several very large solar proton events in years 2000-2003 on the neutral middle atmosphere, Adv. Space Res. 35, 445-450, doi:10.1016/j.asr.2004.09.006.

Jackman, C. H., et al. (2008), Short- and medium-term atmospheric constituent effects of very large solar proton events, Atmos. Chem. Phys., 8, 765-785, doi:10.5194/acp-8-765-2008.

Jackman, C. H., D. R. Marsh, F. M. Vitt, R. R. Garcia, C. E. Randall, E. L. Fleming, and S. M. Frith (2009), Long-term middle atmospheric influence of very large solar proton events, J. Geophys. Res., 114, D11304, doi:10.1029/2008JD011415.

Langematz, U., J. L. Grenfell, K. Matthes, P. Mieth, M. Kunze, B. Steil, and C. Brühl (2005), Chemical effects in 11-year solar cycle simulations with the Freie Universität Berlin Climate Middle Atmosphere Mode with online chemistry (FUB-CMAM-CHEM), Geophys. Res. Lett., 32 , L13803, doi:10.1029/2005GL022686.

Lary, D. (1997), Catalytic destruction of stratospheric ozone, J. Geophys. Res., 102, 21,515-21,526, doi:10.1029/97JD00912.

López-Puertas, M., B. Funke, S. Gil-López, T. von Clarmann, G. P. Stiller, M. Höpfner, S. Kellmann, G. Mengistu Tsidu, H. Fischer, and C. H. Jackman (2005), $\mathrm{HNO}_{3}, \mathrm{~N}_{2} \mathrm{O}_{5}$, and $\mathrm{ClONO}_{2}$ enhancements after the October-November 2003 solar proton events, J. Geophys. Res., 110, A09S44, doi:10.1029/2005JA011051.

López-Puertas, M., B. Funke, T. von Clarmann, H. Fischer, and G. P. Stiller (2006), The stratospheric and mesospheric $\mathrm{NO}_{\mathrm{y}}$ in the 2002-2004 polar winters as measured by MIPAS/ENVISAT, Space Sci. Rev., 125 , 403-416, doi:10.1007/s11214-006-9073-2.

Lyons, L., and R. Thorne (1973), Equilibrium structure of radiation belt electrons, J. Geophys. Res., 78, 2142-2149, doi:10.1029/JA078i013p02142.

Meredith, N. P., R. B. Horne, R. M. Thorne, D. Summers, and R. R. Anderson (2004), Substorm dependence of plasmaspheric hiss, J. Geophys. Res., 109, A06209, doi:10.1029/2004JA010387.

Meredith, N. P., R. B. Horne, S. A. Glauert, R. M. Thorne, D. Summers, J. M. Albert, and R. R. Anderson (2006), Energetic outer zone electron loss timescales during low geomagnetic activity, J. Geophys. Res., 111, A05212, doi:10.1029/2005JA011516.

Randall, C. E., et al. (2005), Stratospheric effects of energetic particle precipitation in 2003-2004, Geophys. Res. Lett., 32, L05802, doi:10.1029/ 2004GL022003.

Randall, C. E., V. L. Harvey, C. S. Singleton, S. M. Bailey, P. F. Bernath, M. Codrescu, H. Nakajima, and J. M. Russell III (2007), Energetic particle precipitation effects on the Southern Hemisphere stratosphere in 1992-2005, J. Geophys. Res., 112, D08308, doi:10.1029/ 2006JD007696.

Reeves, G. D., K. L. McAdams, R. H. W. Friedel, and T. P. O'Brien (2003), Acceleration and loss of relativistic electrons during geomagnetic storms, Geophys. Res. Lett., 30(10), 1529, doi:10.1029/2002GL016513.

Rodger, C. J. (2003), Subionospheric VLF perturbations associated with lightning discharges, J. Atmos. Sol. Terr. Phys., 65, 591-606, doi:10.1016/S1364-6826(02)00325-5.

Rodger, C. J., O. A. Molchanov, and N. R. Thomson (1998), Relaxation of transient ionization in the lower ionosphere, J. Geophys. Res., 103, 69696975, doi:10.1029/98JA00016.

Rodger, C. J., M. A. Clilverd, P. T. Verronen, T. Ulich, M. J. Jarvis, and E. Turunen (2006), Dynamic geomagnetic rigidity cutoff variations during a solar proton event, J. Geophys. Res., 111, A04222, doi:10.1029/ 2005JA011395.

Rodger, C. J., M. A. Clilverd, N. R. Thomson, R. J. Gamble, A. Seppälä, E. Turunen, N. P. Meredith, M. Parrot, J. A. Sauvaud, and J.-J. Berthelier (2007), Radiation belt electron precipitation into the atmosphere: Recovery from a geomagnetic storm, J. Geophys. Res., 112, A11307, doi:10.1029/2007JA012383.

Rodger, C. J., T. Raita, M. A. Clilverd, A. Seppälä, S. Dietrich, N. R. Thomson, and T. Ulich (2008), Observations of relativistic electron precipitation from the radiation belts driven by EMIC waves, Geophys. Res. Lett., 35, L16106, doi:10.1029/2008GL034804.

Rodger, C. J., M. A. Clilverd, J. C. Green, and M. M. Lam (2010), Use of POES SEM-2 observations to examine radiation belt dynamics and energetic electron precipitation into the atmosphere, J. Geophys. Res., 115, A04202, doi:10.1029/2008JA014023.

Rozanov, E., L. Callis, M. Schlesinger, F. Yang, N. Andronova, and V. Zubov (2005), Atmospheric response to $\mathrm{NO}_{\mathrm{y}}$ source due to energetic electron precipitation, Geophys. Res. Lett., 32, L14811, doi:10.1029/2005GL023041.

Sauvaud, J. A., T. Moreau, R. Maggiolo, J.-P. Treilhou, C. Jacquey, A. Cros, J. Coutelier, J. Rouzaud, E. Penou, and M. Gangloff (2006), High-energy electron detection onboard DEMETER: The IDP spectrometer, description and first results on the inner belt, Planet. Space Sci., 54, 502-511, doi:10.1016/j.pss.2005.10.019.

Seppälä, A., P. T. Verronen, V. F. Sofieva, J. Tamminen, E. Kyrölä, C. J. Rodger, and M. A. Clilverd (2006), Destruction of the tertiary ozone maximum during a solar proton event, Geophys. Res. Lett., 33 , L07804, doi:10.1029/2005GL025571.

Seppälä, A., M. A. Clilverd, and C. J. Rodger (2007), $\mathrm{NO}_{x}$ enhancements in the middle atmosphere during 2003-2004 polar winter: Relative significance of solar proton events and the aurora as a source, J. Geophys. Res. 112, D23303, doi:10.1029/2006JD008326.

Seppälä, A., M. A. Clilverd, C. J. Rodger, P. T. Verronen, and E. Turunen (2008), The effects of hard-spectra solar proton events on the middle atmosphere, J. Geophys. Res., 113, A11311, doi:10.1029/2008JA013517.

Seppälä, A., C. E. Randall, M. A. Clilverd, E. Rozanov, and C. J. Rodger (2009), Geomagnetic activity and polar surface level air temperature variability, J. Geophys. Res., 114, A10312, doi:10.1029/2008JA014029. 
Sharma, A. S., Y. Kamide, and G. S. Lakhina (Eds.) (2004), Disturbances in Geospace: The Storm-Substorm Relationship, Geophys. Monogr. Ser. vol. 142, AGU, Washington, D. C.

Shea, M. A., and D. F. Smart (1995), A comparison of energetic solar proton events during the declining phase of four solar cycles (cycles 19-22), $A d v$. Space Res., 16, 37-46, doi:10.1016/0273-1177(95)00312-3.

Shimazaki, T. (1971), Effective eddy diffusion coefficient and atmospheric composition in the lower thermosphere, J. Atmos. Terr. Phys., 33, 1383-1401, doi:10.1016/0021-9169(71)90011-0.

Spjeldvik, W. N., and R. M. Thorne (1975a), The cause of storm after effects in the middle latitude D-region ionosphere, J. Atmos. Terr. Phys., 37, 777-795, doi:10.1016/0021-9169(75)90021-5.

Spjeldvik, W. N., and R. M. Thorne (1975b), A simplified D-region model and its application to magnetic storm after effects, J. Atmos. Terr. Phys. 37, 1313-1325, doi:10.1016/0021-9169(75)90124-5.

Störmer, C. (1930), Periodische elektronenbahnen im feld eines elementarmagnetron und ihre anwendung auf bruches modellversuche und auf eschenhagens elementarwellen des erdmagnetismus, Z. Astrophys., 1, 237-274.

Thomson, N. R. (1993), Experimental daytime VLF ionospheric parameters, J. Atmos. Terr. Phys., 55, 173-184, doi:10.1016/0021-9169(93)90122-F.

Thomson, N. R., and M. A. Clilverd (2000), Solar cycle changes in daytime VLF subionospheric attenuation, J. Atmos. Sol. Terr. Phys., 62, 601-608, doi:10.1016/S1364-6826(00)00026-2.

Thomson, N. R., C. J. Rodger, and M. A. Clilverd (2005), Large solar flares and their ionospheric D-region enhancements, J. Geophys. Res., 110, A06306, doi:10.1029/2005JA011008.

Thorne, R. M., and T. R. Larsen (1976), An investigation of relativistic electron precipitation events and their association with magnetic substorm activity, J. Geophys. Res., 81, 5501-5506, doi:10.1029/JA081i031p05501.

Tobiska, W. K., T. Woods, F. Eparvier, R. Viereck, L. D. B. Floyd G. Rottman, and O. R. White (2000), The SOLAR2000 empirical solar irradiance model and forecast tool, J. Atmos. Terr. Phys., 62, 1233-1250, doi:10.1016/S1364-6826(00)00070-5.
Turunen, E., P. T. Verronen, A. Seppälä, C. J. Rodger, M. A. Clilverd, J. Tamminen, C. F. Enell, and T. Ulich (2009), Impact of different precipitation energies on $\mathrm{NO}_{x}$ generation during geomagnetic storms, J. Atmos. Sol. Terr. Phys., 71, 1176-1189, doi:10.1016/j.jastp.2008.07.005.

Verronen, P. T., E. Turunen, T. Ulich, and E. Kyrölä (2002), Modelling the effects of the October 1989 solar proton event on mesospheric odd nitrogen using a detailed ion and neutral chemistry model, Ann. Geophys., 20 , 1967-1976, doi:10.5194/angeo-20-1967-2002.

Verronen, P. T., A. Seppälä, M. A. Clilverd, C. J. Rodger, E. Kyrölä, C.-F Enell, T. Ulich, and E. Turunen (2005), Diurnal variation of ozone depletion during the October-November 2003 solar proton events, J. Geophys. Res., 110, A09S32, doi:10.1029/2004JA010932.

World Meteorological Organization (WMO) (2007), Scientific assessment of ozone depletion 2006: Global ozone research and monitoring project, Rep. 50, 572 pp., Geneva, Switzerland.

M. A. Clilverd and A. Seppälä, British Antarctic Survey, High Cross, Madingley Road, Cambridge CB3 0ET, UK. (macl@bas.ac.uk; annika. seppala@bas.ac.uk)

R. J. Gamble, C. J. Rodger, and N. R. Thomson, Department of Physics, University of Otago, P. O. Box 56, Dunedin 9016, New Zealand (rgamble@physics.otago.ac.nz; crodger@physics.otago.ac.nz; thomson@ physics.otago.ac.nz)

M. Parrot, Laboratoire de l'Environnement et de l'Espace, 3A Avenue de la Recherche Scientifique, F-45071 Orleans Cedex 2, France. (mparrot@ cnrs-orleans.fr)

J. A. Sauvaud, Centre d'Etude Spatiale des Rayonnements, 9 Avenue du Colonel Roche F-31028, Toulouse Cedex 4, France. (sauvaud@cesr.fr)

T. Ulich, Sodankylä Geophysical Observatory, University of Oulu, Sodankylä FIN-99600, Finland. (thu@sgo.fi) 